\title{
UAV Control System Based on Back-Stepping and Active Disturbance Rejection Control
}

\author{
Chen Linqi ${ }^{1}$, Li Tinghui ${ }^{1}$ \\ 1. College of Electronic Engineering, Guangxi Normal University, Guilin Guangxi 541004, China \\ linqi_chen@qq.com, tinghuili@gxnu.edu.cn
}

\begin{abstract}
This paper combines back-stepping and active disturbance rejection control (ADRC) to form an integrated controller for quad-rotor UAV with multiple uncertainties. First, the aerodynamics model of the quad-rotor UAV is analyzed, and the control law of the back-stepping is deduced. Second, after analyzing the back-stepping control law, it can be rewritten and integrated with ADRC. In order to satisfy the demand of back-stepping, finite-time convergent third-order differentiator is used instead of the tracking differentiator (TD).Third, the closed-loop feedback controller for the system is established. Finally, simulation experiments under the MATLAB environment show that the integrated controller improves convergence speed and control precision.
\end{abstract}

Keywords-Quad-rotor UAV; Back-stepping control; Active disturbance rejection control (ADRC); Nonlinear control; Algorithm combination

\section{Introduction}

Quad-rotor UAV is a kind of small UAV. Compared with fixed-wing and helicopter-type aircraft, it has higher maneuverability and more freedom and it can shuttle flexibly in narrow and complex space. The Quad-rotor UAV has simple structure and low cost. Now days, it has been widely used in search, environmental awareness, natural disasters, environmental monitoring and peripheral surveillance [1].

In recent years, Quad-rotor UAVs have developed rapidly in China. But at present, commercial UAVs still large-scale use the classical PID control. PID control algorithm has obvious defects for the under-actuated, strong coupling and nonlinear system like Quad-rotor UAVs. Domestic and foreign scholars have proposed new improvements or new control methods. PID control algorithms are improved in [2]. Back-stepping method is improved in [3]. Combination of PD control and back-stepping method is proposed in [4]. Synovium reconstruction and back-stepping method are integrated in [5-6]. Linear and nonlinear ADRC algorithm have been used in [7].

Although the convergence speed of back-stepping control law is not ideal and the anti-jamming performance is poor, there is almost no steady-state error. ADRC has nice anti-interference ability and convergence speed is no less than PID control, but there are more or less steady-state error. The combination of back-stepping and ADRC makes up for its shortcomings. The integrated controller improves convergence speed and control precision.

This paper is organized as follows. In Section 2, aerodynamics model analysis and Back-stepping deduction are presented. Back-stepping control law analysis and introduction of the ADRC are presented in Section 3. The closed-loop feedback controller system is established in Section 4. Simulation results are shown in Section 5. The paper ends with a few concluding remarks in Section 6.

\section{Aerodynamics model analysis and Back-stepping deduction}

\section{A. Aerodynamics model analysis}

Quad-rotor UAV is a 4-input, 6-output under-actuated model, and each channel has a strong coupling. In most cases, the body of the Quad-rotor UAV can be regarded as rigid and symmetrical. The aerodynamics model can be described as follows in [8]:

$$
\left\{\begin{array}{c}
\ddot{\mathrm{x}}=(\cos \phi \sin \theta \cos \psi+\sin \phi \sin \psi) \frac{\mathrm{U}_{1}}{\mathrm{~m}}-\frac{\mathrm{k}_{1}}{\mathrm{~m}} \dot{\mathrm{x}} \\
\ddot{\mathrm{y}}=(\cos \phi \sin \theta \sin \psi-\sin \phi \cos \psi) \frac{\mathrm{U}_{1}}{\mathrm{~m}}-\frac{\mathrm{k}_{2}}{\mathrm{~m}} \dot{\mathrm{y}} \\
\ddot{\mathrm{z}}=(\cos \phi \cos \theta) \frac{\mathrm{U}_{1}}{\mathrm{~m}}-\mathrm{g}-\frac{\mathrm{k}_{3}}{\mathrm{~m}} \dot{\mathrm{z}} \\
\ddot{\phi}=\dot{\theta} \dot{\psi}\left(\frac{I_{y}-I_{z}}{I_{x}}\right)+\frac{1}{\mathrm{I}_{\mathrm{x}}} \mathrm{U}_{2}-\frac{\mathrm{lk}_{4}}{\mathrm{I}_{\mathrm{x}}} \dot{\phi}+d_{1} \\
\ddot{\theta}=\dot{\phi} \dot{\psi}\left(\frac{I_{z}-I_{x}}{I_{x}}\right)+\frac{1}{\mathrm{I}_{\mathrm{y}}} \mathrm{U}_{3}-\frac{1 \mathrm{k}_{5}}{\mathrm{I}_{\mathrm{y}}} \dot{\theta}+d_{2} \\
\ddot{\psi}=\dot{\phi} \dot{\theta}\left(\frac{I_{x}-I_{y}}{I_{z}}\right)+\frac{1}{\mathrm{I}_{\mathrm{z}}} \mathrm{U}_{4}-\frac{\mathrm{lk}_{6}}{\mathrm{I}_{\mathrm{z}}} \dot{\psi}+d_{3}
\end{array}\right.
$$

Among them, $U_{1}, U_{2}, U_{3}, U_{4}$ are the four control inputs of 
UAV. $x, y, z$ represent the position of the UAV. $\phi, \theta, \psi$ are Euler angles, describing the attitude of the UAV. $\mathrm{k}_{1}, \mathrm{k}_{2}, \mathrm{k}_{3}, \mathrm{k}_{4}, \mathrm{k}_{5}, \mathrm{k}_{6}$ are the air drag coefficient of UAV. $\mathrm{I}_{\mathrm{x}}, \mathrm{I}_{\mathrm{y}}, \mathrm{I}_{\mathrm{z}}$ are three axis inertia of UAV respectively. $\mathrm{l}$ is the diagonal length of the UAV, $g$ is the acceleration constant of gravity, $\mathrm{m}$ is the total quality of UAV. $d_{1}, d_{2}, d_{3}$ are attitudes disturbances of $\mathrm{UAV}$, each of them is composed of random disturbances and sinusoidal disturbances.

As the UAV model, UAV control is generally divided into two parts, position control and attitude control. Position control mainly controls the three-dimensional coordinates of UAV in space, and also affected by attitude angle. Attitude control is mainly controlled by three Euler angles. In summary, attitude control of UAV is an important part, and the integrated controller is mainly used in attitude control.

\section{B. Back-Stepping deduction}

In order to get the back-stepping control law, the dynamics model of the quad-rotor UAV needs to be rewritten as follows:

$$
\ddot{X}=f(X)+g(X) U
$$

In the formula, $\mathrm{X}=[\mathrm{x}, \mathrm{y}, \mathrm{z}, \phi, \theta, \psi]$. Because $\mathrm{U}_{1}$ controls the positions of $\mathrm{x}, \mathrm{y}, \mathrm{z}$ axes simultaneously, $\mathrm{U}_{1}$ is decomposed to $U_{1 \mathrm{x}}, \mathrm{U}_{1 \mathrm{y}}, \mathrm{U}_{1 \mathrm{z}}$, So the $\mathrm{U}$ vector is in the following form: $U=\left[U_{1 \mathrm{x}}, \mathrm{U}_{1 \mathrm{y}}, \mathrm{U}_{1 \mathrm{z}}, \mathrm{U}_{2}, \mathrm{U}_{3}, \mathrm{U}_{4}\right]$. The original $\mathrm{g}(\mathrm{X})$ and $\mathrm{f}(\mathrm{X})$ are rewritten as follows:

$$
\begin{aligned}
& \mathrm{g}(\mathrm{X})=\left[\begin{array}{c}
(\cos \phi \sin \theta \cos \psi+\sin \phi \sin \psi) \frac{1}{\mathrm{~m}} \\
(\cos \phi \sin \theta \sin \psi-\sin \phi \cos \psi) \frac{1}{\mathrm{~m}} \\
(\cos \phi \cos \theta) \frac{1}{\mathrm{~m}} \\
\frac{1}{\mathrm{I}_{\mathrm{x}}} \\
\frac{1}{\mathrm{I}_{\mathrm{y}}} \\
\frac{1}{\mathrm{I}_{\mathrm{z}}}
\end{array}\right] \\
& \mathrm{f}(\mathrm{X})=\left[\begin{array}{c}
-\frac{\mathrm{k}_{1}}{\mathrm{~m}} \dot{\mathrm{x}} \\
-\frac{\mathrm{k}_{2}}{\mathrm{~m}} \dot{\mathrm{y}} \\
-\mathrm{g}-\frac{\mathrm{k}_{3}}{\mathrm{~m}} \dot{\mathrm{z}} \\
\dot{\theta} \dot{\psi}\left(\frac{I_{y}-I_{z}}{I_{x}}\right)-\frac{1 \mathrm{k}_{4}}{\mathrm{I}_{\mathrm{x}}} \dot{\phi} \\
\dot{\phi} \dot{\psi}\left(\frac{I_{z}-I_{x}}{I_{x}}\right)-\frac{1 \mathrm{k}_{5}}{\mathrm{I}_{\mathrm{y}}} \dot{\theta} \\
\dot{\phi} \dot{\theta}\left(\frac{I_{x}-I_{y}}{I_{z}}\right)-\frac{1 \mathrm{k}_{6}}{\mathrm{I}_{z}} \dot{\psi}
\end{array}\right]
\end{aligned}
$$

The specific process of designing the control rate by back-stepping is as follows:

Definition 1: Define expected value: $\mathrm{X}_{\mathrm{d}}=\left[\mathrm{x}_{\mathrm{d}}, \mathrm{y}_{\mathrm{d}}, \mathrm{z}_{\mathrm{d}}, \phi_{\mathrm{d}}, \theta_{\mathrm{d}}, \psi_{\mathrm{d}}\right]$.

Definition 2: Introducing the first tracking error: $\mathrm{e}_{1}=\mathrm{X}_{\mathrm{d}}$ $\mathrm{X}$.

Select the first Lyapunov function and derivation:

$$
\begin{gathered}
\mathrm{V}_{1}\left(\mathrm{e}_{1}\right)=\frac{1}{2} \mathrm{e}_{1}^{2} \\
\mathrm{~V}_{1}\left(\dot{\mathrm{e}_{1}}\right)=\mathrm{e}_{1} \dot{\mathrm{e}_{1}}=\mathrm{e}_{1}\left(\dot{\mathrm{X}_{\mathrm{d}}}-\dot{\mathrm{X}}\right)
\end{gathered}
$$

Definition 3: In order to make $\mathrm{V}_{1}\left(\mathrm{e}_{1}\right)$ converge, define $\alpha_{1}=\dot{X_{d}}+k_{1} e_{1}$ instead of $\dot{X}$ in (6).

$$
\mathrm{V}_{1}\left(\mathrm{e}_{1}\right)=\mathrm{e}_{1}\left(\dot{\mathrm{X}_{\mathrm{d}}}-\dot{\mathrm{X}}\right)=\mathrm{e}_{1}\left(\dot{\mathrm{X}_{\mathrm{d}}}-\dot{\mathrm{X}_{\mathrm{d}}}-\mathrm{k}_{1} \mathrm{e}_{1}\right)=-\mathrm{k}_{1} \mathrm{e}_{1}^{2} \leq 0
$$

Remark 1: In (7), $\mathrm{k}_{1} \geq 0$. When the first tracking error decreases to 0 , the first Lyapunov function converges stably.

Definition 4: Introducing the secnd tracking error and derivation:

$$
\begin{gathered}
e_{2}=\dot{X}-\alpha_{1} \\
\dot{e_{2}}=\ddot{X}-\dot{\alpha_{1}}=f(X)+g(X) U-\ddot{X_{d}}-k_{1} \dot{e_{1}}
\end{gathered}
$$

Select the second Lyapunov function and derivation:

$$
\begin{gathered}
\mathrm{V}_{2}\left(\mathrm{e}_{1}, \mathrm{e}_{2}\right)=\frac{1}{2}\left(\mathrm{e}_{1}^{2}+\mathrm{e}_{2}^{2}\right) \\
\mathrm{V}_{2}\left(\mathrm{e}_{1}, \mathrm{e}_{2}\right)=-\mathrm{k}_{1} \mathrm{e}_{1}^{2}+\mathrm{e}_{2}\left(-\mathrm{e}_{1}+\mathrm{f}(\mathrm{X})+\mathrm{g}(\mathrm{X}) \mathrm{U}-\ddot{\mathrm{X}_{\mathrm{d}}}-\mathrm{k}_{1} \dot{\mathrm{e}_{1}}\right)
\end{gathered}
$$

Definition 5: In order to make $\mathrm{V}_{2}\left(\mathrm{e}_{1}, \mathrm{e}_{2}\right)$ converge, back-stepping control law can be defined as:

$$
\mathrm{U}=\frac{1}{\mathrm{~g}(\mathrm{X})}\left(\mathrm{e}_{1}-\mathrm{f}(\mathrm{X})+\ddot{X}_{\mathrm{d}}+\mathrm{k}_{1} \dot{e}_{1}-\mathrm{k}_{2} \mathrm{e}_{2}\right)
$$

Replace the back-stepping control law in (11),

$$
\mathrm{V}_{2}\left(\mathrm{e}_{1}, \mathrm{e}_{2}\right)=-\mathrm{k}_{1} \mathrm{e}_{1}^{2}-\mathrm{k}_{2} \mathrm{e}_{2}^{2} \leq 0
$$

Remark 1: In (13), $\mathrm{k}_{1} \geq 0 \mathrm{k}_{2} \geq 0$. When the first tracking error and second tracking error decreases to 0 , the second Lyapunov function converges stably. The back-stepping control law has been derived as follow:

$$
U=\frac{1}{g(X)}\left(e_{1}-f(X)+\ddot{X_{d}}+k_{1} \dot{e}_{1}-k_{2} e_{2}\right)
$$


III. Back-stepping control law analysis and introduction of the ADRC

\section{A. Back-stepping control law analysis}

According to the derivation process of back-stepping, expand (8) as follow:

$$
e_{2}=\dot{X}-\alpha_{1}=\dot{X}-\dot{X_{d}}-k_{1} e_{1}=-\dot{e_{1}}-k_{1} e_{1}
$$

Replaced $e_{2}$ in (12), leaving only the $e_{1}$ and $\dot{e}_{1}$ and merging them to form the following control laws.

$$
U=\frac{1}{g(X)}\left(\left(k_{1} k_{2}+1\right) e_{1}+\left(k_{1}+k_{2}\right) \dot{e_{1}}-f(x)+\ddot{X}_{d}\right)
$$

Redefine the parameters of $e_{1}$ and $\dot{e_{1}}$, the control law can be rewritten as follows.

$$
\left.\begin{array}{c}
\left(k_{1} k_{2}+1\right)=k_{p} \\
\left(k_{1}+k_{2}\right)=k_{d}
\end{array}\right\}
$$

The $g(X)$ can be regarded as a constant in every channel of the vector. $k_{p} e_{1}+k_{d} e_{1}$ can be understood as linear differential control. ADRC algorithm is introduced here.

\section{B. ADRC algorithm introduced}

The ADRC is composed of three parts: tracking differentiator (TD), extended state observer (ESO) and nonlinear state error feedback (NLSEF).

Due to the control requirement of back-stepping method, we need the second differential signal of the target value. The original TD of ADRC can't obtain the second differential signal. At this place, using the finite-time convergent third-order differentiator to replace the TD to obtain the value of $\ddot{X_{d}}$. The algorithm for finite-time convergent third-order differentiator is as follows:

$$
\left\{\begin{array}{c}
\dot{x_{1}}=x_{2} \\
\dot{x_{2}}=x_{3} \\
\varepsilon^{3} \dot{x_{3}}=-2^{\frac{3}{5}} \cdot 4\left(x_{1}-v(t)+\left(\varepsilon x_{2}\right)^{\frac{9}{7}}\right)^{\frac{1}{3}}-4\left(\varepsilon^{2} x_{3}\right)^{\frac{3}{5}}
\end{array}\right.
$$

where $v(t)$ is the input value at any time. $x_{1}$ is the transition process of $v(t) . x_{2}$ is the first derivative of $x_{1}, x_{3}$ is the second derivative of $x_{1}$.

ESO is used for state observation. The algorithm is as follows:

$$
\left\{\begin{array}{c}
e=z_{1}-y \\
\dot{z_{1}}=z_{2}-\beta_{01} e \\
\dot{z_{2}=z_{3}-\beta_{02}} \operatorname{fal}(e, 0.5, \sigma)+b u \\
\dot{z_{3}=-\beta_{03}} \operatorname{fal}(e, 0.25, \sigma)
\end{array}\right.
$$

where $u, y$ correspond to the input and output of the controlled object. $b$ is the gain coefficient, $z_{1}$ is the estimated value of the output of the controlled object. $z_{2}$ is the first derivative of the estimated value of the output of the controlled object. $z_{3}$ is the estimation of disturbance of control object.

NLSEF is as follows:

$$
u=k_{1} f a l\left(e_{1}, \alpha_{1}, \sigma_{1}\right)+k_{2} \operatorname{fal}\left(e_{2}, \alpha_{2}, \sigma_{2}\right)
$$

where $e_{1}=X_{d}-X=X_{d}-\widetilde{X}=X_{d}-z_{1}$ is the first error with estimated value $e_{2}$ is derivative of $e_{1}$ correspond to the second error.

The fal function is an important nonlinear function as follows:

$$
f a l(e, \alpha, \sigma)= \begin{cases}|e|^{\alpha} \operatorname{sign}(e) & |e|>\sigma \\ e / \sigma^{1-\alpha} & |e| \leq \sigma\end{cases}
$$

The integrated control law is obtained by replacing the $k_{p} e_{1}+k_{d} e_{1}$ in the back-stepping control law with NLSEF of the ADRC algorithm. The total disturbance estimation is subtracted from the integrated control law, and the final integrated control law is shown below:

$$
\begin{aligned}
& U=\frac{1}{g(X)}\left(k_{1} f a l\left(e_{1}, \alpha_{1}, \sigma_{1}\right)+k_{2} f a l\left(e_{2}, \alpha_{2}, \sigma_{2}\right)-f(X)+\right. \\
& \left.\ddot{x_{d}}\right)-z_{3} / b
\end{aligned}
$$

IV. The closed-loop feedback control system

\section{A. Integrated controller}

The final integrated controller in each channel is depicted in Fig 1. 


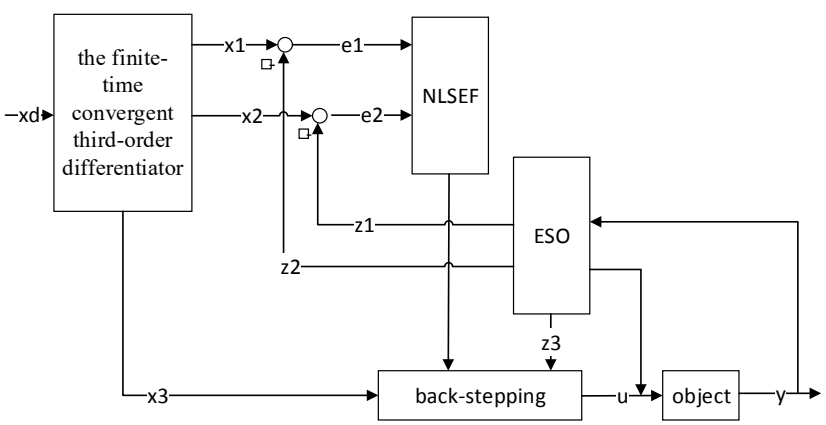

Fig.1 Block diagram of the principle of control algorithm

The objective value $x_{d}$ is input to a finite-time convergent third-order differentiator, the transition process is arranged, and the first-order and second-order derivatives are obtained.

The ESO estimates the state of motion and the total disturbance of the object according to the control variables and the output of the controlled object.

Combining the NLSEF and back-stepping control rate, we can get the integrated control law to control the target.

\section{B. Control system}

The control system of the whole quad-rotor UAV is depicted in Fig 2.

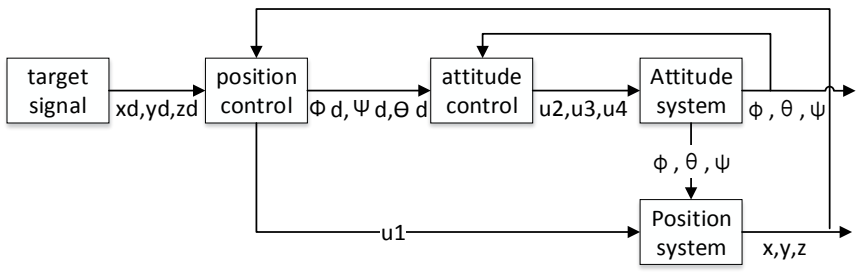

Fig.2 UAV control structure block diagram

The position control algorithm obtains the control variable $\mathrm{U} 1$ entering the position system, and calculates the attitude angle of the UAV target as the input of attitude control. The attitude control algorithm obtains the control volume U2, U3 and U4 into the attitude system. The output information of position model and attitude model is fed back to position control and attitude control to form closed-loop feedback control.

\section{V.Simulation results}

\section{A. Attitude loop simulation}

In order to verify the effectiveness of integrated control law, attitude loop simulation experiments are carried out in MATLAB environment. The target is to make UAV reach the specified target attitude angle, and disturbance is added. Take the pitch angle as an example, control the pitch angle to 30 angle.

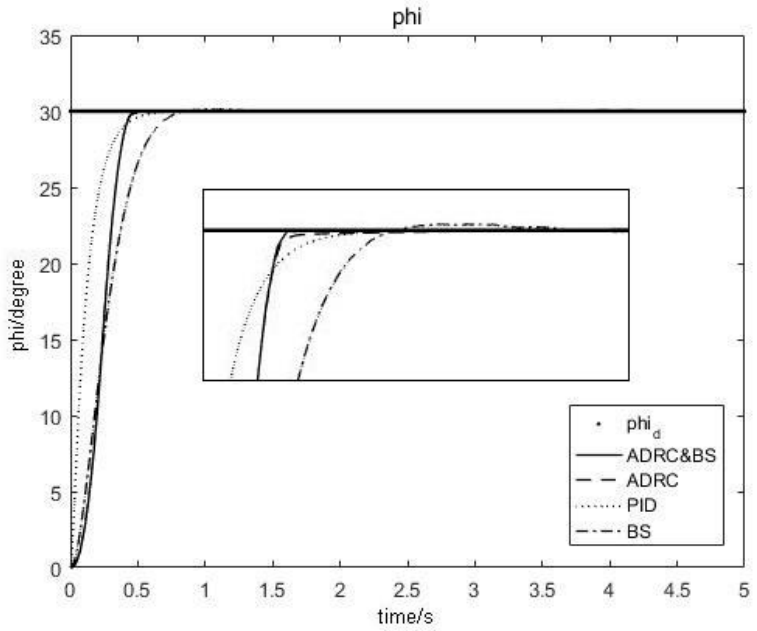

Fig. 3 Contrast diagram of pitch control

It can be seen that the ADRC and the integrated control law algorithm have obvious advantages. In the enlarged image, the ADRC has obvious deceleration near the target value, and the integrated control law solves this problem.

\begin{tabular}{|c|c|c|c|c|}
\hline & $\begin{array}{c}\text { back-step } \\
\text { ping }\end{array}$ & $\begin{array}{c}\text { Series } \\
\text { PID }\end{array}$ & ADRC & $\begin{array}{c}\text { ADRC } \\
\& B S\end{array}$ \\
\hline $\begin{array}{c}\text { First time to } \\
\text { target }\left(t_{p 1} / s\right)\end{array}$ & 0.8460 & 0.9820 & 0.8680 & 0.5070 \\
\hline $\begin{array}{c}\text { The time to } \\
\text { reach the } \\
\text { target }\left(t_{p 2} / s\right)\end{array}$ & 0.7500 & 0.7750 & 0.5430 & 0.4680 \\
\hline overshoot $(\%)$ & $0.45 \%$ & 0 & 0 & 0 \\
\hline $\begin{array}{c}\text { Stable time } \\
\left(t_{s} / s\right)\end{array}$ & 2.4520 & 0.9820 & 0.8680 & 0.5070 \\
\hline
\end{tabular}

Table I Performance index of each control algorithm

When adjusting parameters in each algorithm, non-overshoot is important goal. So only the back-stepping algorithm has overshoot phenomenon. According to table 1. In all control algorithms, the pure back-stepping method has the worst control effect. The convergence speed of ADRC is only $0.12 \mathrm{~s}$ faster than cascade PID, but ADRC is $0.23 \mathrm{~s}$ faster 
than the target angle, which shows that ADRC has obvious deceleration when approaching the target angle. The convergence time of integrated control law is more than $0.3 \mathrm{~s}$ faster than other algorithms, which shows the advantage of integrated control law in attitude control.

\section{B. Position loop simulation}

In position control, the integrated control law is still adopted, and compared with the non-linear PD control algorithm in [4]. Interference noise is added to the attitude loop. The following is the comparison of position simulation control results.

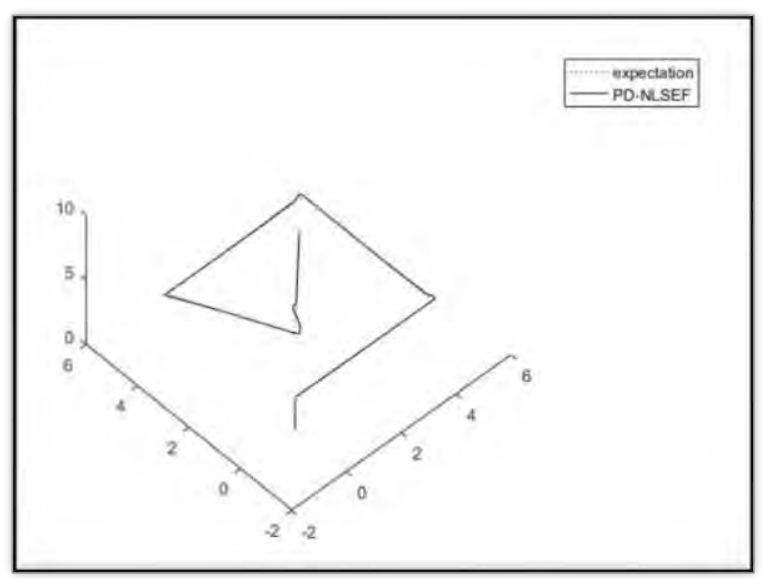

Fig.4 PD nonlinear control position loop

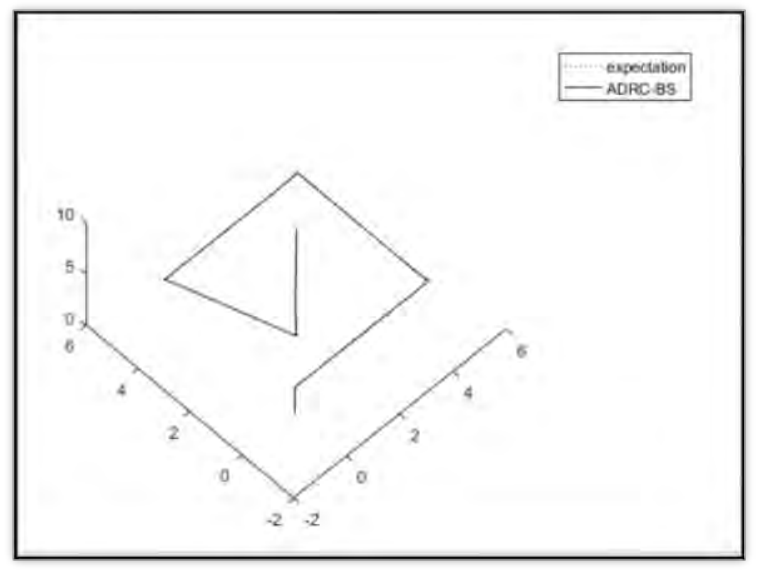

Fig.5 The integrated control law control position loop

The two algorithms are based on the starting position $(0,0$, $0)$, tracking the trajectory of the rectangle to simulate flight.

In Fig 4, the maximum error of $x, y, z$ axis is $0.13 \mathrm{~m}$, $0.30 \mathrm{~m}, 0.10 \mathrm{~m}$.

In Fig 5, the maximum error of $x, y, z$ axis is $0.04 \mathrm{~m}$,
$0.09 \mathrm{~m}, 0.08 \mathrm{~m}$.

The integrated control law are introduced in position control to make the position error accurate to centimeter level.

\section{Conclusion}

This paper combines the back-stepping method and ADRC to form the integrated control law. The integrated control law combines the advantages of back-stepping and ADRC. In simulation experiments, the attitude loop and position loop control of the quad-rotor UAV can be realized well. The simulation results show that the integrated controller improves the convergence speed and control accuracy of UAV in position control.

\section{ACKNOWLEDGMENT}

This work was financially supported by the National Natural Science Foundation of China (Grant No. 61264008).

\section{REFERENCES}

[1] Idries A, Mohamed N, Jawhar I, et al. Challenges of developing UAV applications: a project management view $[\mathrm{J}]$. International Conference on Industrial Engineering and Operations Management . 2015:1-10.

[2] Zuo Z. Trajectory tracking control design with command filtered compensation for a quadrotor $[\mathrm{J}]$. IET Control Theory \& Applications, 2010, 4( 11): 2343 - 2355.

[3] TAN L, LU L, JIN G. Attitude stabilization control of a quadrotor helicopter using integral Back-stepping[C]// International Conference on Automatic Control and Artificial Intelligence. IET, 2013:573-577.

[4] Basri M A M, Husain A R, Danapalasingam K A. Enhanced back-stepping controller design with application to autonomous quadrotor unmanned aerial vehicle $[\mathrm{J}]$. Journal of Intelligent \& robotic Systems, 2014, 79(2):295 - 321.

[5] Wang T, Xie W F, Zhang Y M. Sliding mode reconfigurable control using information on the control effectiveness of actuators $[\mathrm{J}]$. Journal of Aerospace Engineering, 2014, 27(3):587 - 596.

[6] CHEN F, JIANG $\mathrm{R}$, ZHANG $\mathrm{K}$, et al. robust back-stepping sliding-mode control and observer-based fault estimation for quad-rotor UAV $[\mathrm{J}]$. IEEE Transactions on Industrial Electronics, 2016, 63( 8) : $5044-5056$.

[7] Li J, Li R, Zheng H. Quadrotor modeling and control based on Linear Active Disturbance Rejection Control[C]// Control Conference. IEEE, 2016:10651-10656.

[8] XU R, Ümit Özgüner. Sliding mode control of a class of under-actuated systems [J]. Automatica, 2008, 44(1):233-241. 